Alma Mater Studiorum - Università di Bologna DEPARTMENT OF ECONOMICS

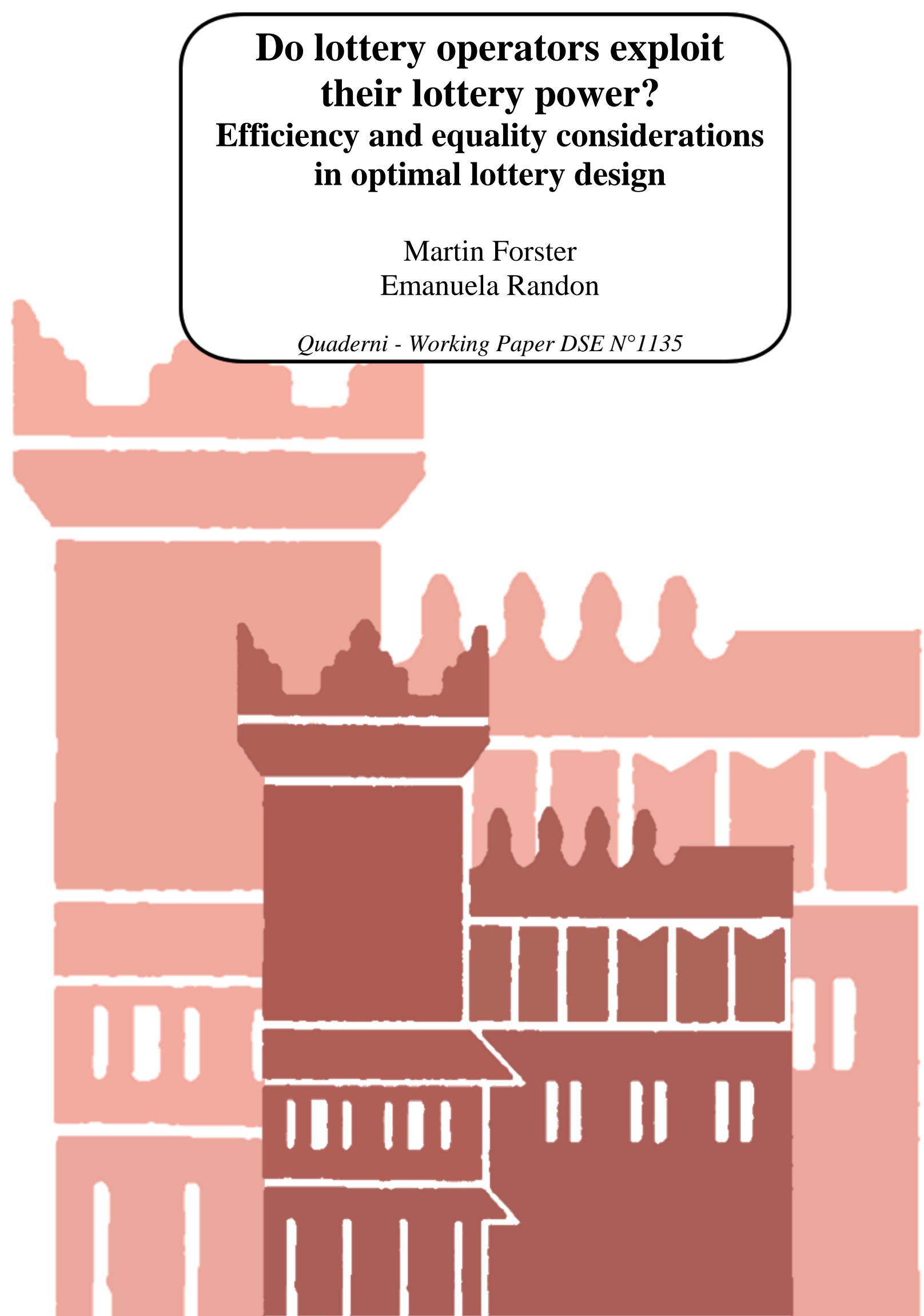




\title{
Do lottery operators exploit their lottery power? Efficiency and equality considerations in optimal lottery design
}

\author{
Martin Forster* and Emanuela Randon ${ }^{\dagger}$
}

October 7, 2019

\begin{abstract}
We study the problem facing the operator of a lottery who is charged with raising revenue for the public finances. Demand for the lottery is a function of both disposable income and the pricing of the game. Departing from the current literature, we show that optimal lottery pricing includes corrections for the degree of inequality and skewness in the income distribution and features of the function relating lottery spend to disposable income. When gross lottery expenditure is regressive, it is optimal for the operator to improve the terms of the game by being more generous with the proportion of spend that is returned to players. The opposite result holds when gross lottery expenditure is progressive. Using results from analysis of the U.K. National Lottery's Saturday game between 1997 and 2013, we show that the effective price was about ten percentage points too low to be efficient, so that the operator was not fully exploiting its lottery power. However, we also show that, were it to have raised its price to improve efficiency, it would have increased inequality.
\end{abstract}

JEL codes: H27, H71, D63

Keywords: Gambling; Lotteries; Public Finances; Inequality

*Department of Economics and Related Studies, University of York, York, U.K. mf8@ york.ac.uk

†Department of Economics, University of Bologna, Bologna, Italy. emanuela.randon@ unibo.it 


\section{Non-technical summary}

National and state lotteries represent big business for countries seeking to raise money for the public finances. Worldwide spend on lotteries is estimated at \$3.4bn in 2019. In 2016, Americans spent about $\$ 80.5 \mathrm{bn}$ on lotteries, Chinese expenditure was approximately \$38bn in 2017 and the figure in the U.K. was $£ 7.2$ bn in 2018-2019. Lotteries are attracting much interest from economists and there is a large body of empirical work which seeks to examine their operation, how good they are at raising revenue for governments, and the characteristics of those who play and those who do not. However, despite the large empirical literature, the theoretical modelling of lotteries is underdeveloped.

We present a theory of how to design a lottery when the operator would like to maximise revenue but faces a population whose members have different levels of income and whose willingness to play the game varies according to the level of prize money offered. We find a new optimal rule for the choice of prize money payout, which takes account of these population-level differences. We compare our rule with a rule that ignores these population-level differences and we show how it affects both the total revenue raised by the lottery and the degree of inequality that the lottery generates.

We apply our model to the U.K.'s state lottery (the 'National Lottery') for the years 19972013. We show that the operator was being more generous with the proportion of money paid out in prizes than is suggested by our model and that it could have increased revenues by about $3.4 \%$ per weekly draw had it acted optimally. However, the operator was also more equitable in its choice of prize money payout, suggesting that it may have been sacrificing revenue in order to be more equitable. 


\section{Introduction}

National and state lotteries represent big business for institutions seeking to raise money for the public finances. Worldwide spend on lotteries is estimated at $\$ 3.4 \mathrm{bn}$ in 2019 and is forecast to grow at a compound rate of 5\% per annum between 2019 and 2024 (WGR, 2019). In the United States during 2016, Americans spent about \$80.5bn on lotteries, with \$22.5bn going to state and local governments (North American Association of State and Provincial Lotteries, 2019). Total spend on the Chinese lottery in 2017 was CNY263bn (approximately \$38bn) (World Lottery Association, 2018) and the U.K.'s National Lottery had sales revenue nearing $£ 7.2 \mathrm{bn}$ in 2018-2019, paying out around $£ 4$.1bn in prize money and generating about $£ 1.7$ for good causes (Camelot UK Lotteries Limited, 2019).

A growing economic literature assesses whether the pricing policies of lottery operators are revenue-maximising and investigates the relationship between the proportion of income spent on lotteries and disposable income. Interest goes back at least as far as Sprowls (1970), who studied the operation of the New York lottery and how it might be redesigned so as to increase sales. Subsequent work has considered both the theory of lottery operation and empirical analysis of games at the country level. Empirical work often estimates the price elasticity of demand for the lottery, so as to assess whether operators price to maximise revenue (are efficient), and estimates the income elasticity of demand, so as to assess the degree of inequality in lottery expenditure.

Despite the growth in both the worldwide lottery business and accompanying economic literature, the theory of the optimal design of lotteries remains underdeveloped. This gap in the literature is surprising, especially given the breadth of empirical literature which addresses questions of efficiency and equity in lottery operation. More limited still is theoretical analysis of how optimal game design impacts the distribution of income; once more, the theory lags behind the empirics.

In this paper, we seek to redress the balance by presenting a theory of optimal lottery design when the operator faces a heterogeneous population of potential players, differentiated both by their income and response to the design of the game. We provide a general formula for revenue-maximising prices which incorporates distributional issues and population heterogeneity. In our most basic model, the lottery operator seeks to choose the lottery's long term effective price, accounting for the fact that the regressive or progressive nature of gross lottery expenditure demands an adjustment away from the optimal price which applies when everyone in the population spends a constant proportion of their disposable income on the lottery. By referencing results from the literature on income inequality and optimal taxation, we show how optimal pricing affects the degree of inequality in the distribution of gross lottery expenditure. Finally, reflecting recent advances in the empirical literature, we show how the framework may be extended to analyse models where play depends on the size of the jackpot and/or the higher moments of the prize distribution.

Our theoretical results show that, the greater the degree of regressivity in gross lottery expenditure the more the operator should increase the proportion of gross lottery expenditure that is returned to the players - the 'return to player proportion', or RTPP - above that which applies when gross lottery expenditure is proportional. We show that the optimal pricing rule in the latter situation is akin to the standard Lerner index rule that applies for a revenue-maximising 
monopolist under zero marginal cost of production. The opposite result holds when gross lottery expenditure is progressive. However, regardless of whether the proportion of expenditure that is returned to players lies above or below that returned under a proportional take, the distribution of gross lottery expenditure is always more equal than that under the standard Lerner index rule. Applying our results to the extensive analysis presented by Wheeler (2018) for the years 19972013, we obtain an optimal RTPP for the U.K. National Lottery's Saturday game of 0.408. This is about ten percentage points less generous than the game's actual RTPP of 0.514, but about seventeen percentage points higher than the RTPP suggested by the standard Lerner index rule. Our results suggest that, if the operator had priced optimally, it would have increased revenue by about $3.4 \%$ (about $£ 700,000$ per weekly draw). Pricing according to the standard Lerner index rule would reduce revenue by about $£ 1.24 \mathrm{~m}$ per draw.

Our results also show that, not only is the RTPP suggested by the standard Lerner index pricing rule the most inefficient of the three RTPPs (the optimal RTPP, the actual RTPP and the Lerner index RTPP), it is also the most regressive, in that the cumulative proportion of gambling income paid by the poorer groups in the population is higher under Lerner index pricing than under the other two. The least regressive is the actual RTPP used by the operator of the National Lottery over the period in question. We conclude that, although the U.K. National Lottery operator was not fully exploiting its monopoly power over the period of analysis, and was therefore losing out on a relatively small amount of revenue in non-rollover Saturday games, it was also setting the least regressive RTPP. It may be argued therefore, that its choice of RTPP was in line with its obligations as laid out in the National Lottery Act 1993, namely that the Secretary of State should 'do his best to ensure that the net proceeds of the National Lottery are as great as possible', while at the same time protecting participants in the lottery by not encouraging excessive play or targeting particular groups.

We review the main background literature in section 2, state and solve our models in section 3 and present our empirical analysis in section 4 . Section 5 concludes.

\section{Background literature}

National and state lotteries offer notoriously poor odds of winning - often the proportion of total monies staked that is returned to the players can be lower than 0.5 - and the economics literature has made a number of attempts to explain why risk neutral or risk averse individuals would bet under such circumstances. ${ }^{1}$ Perez and Humphreys (2013) cite three possible explanations, which are not necessarily mutually exclusive: versions of an expected utility model in which the shape of the utility function permits unfair bets (Friedman and Savage, 1948); prospect theory, in which the size of the jackpot drives demand (Kahneman and Tversky, 1979; Forrest et al., 2002); treating lottery participation as being a form of entertainment, of hope, or a chance to 'buy a dream' (Maeda, 2008; Conlisk, 1993; Clotfelter and Cook, 1989; Forrest et al., 2002). Other contributions suggest that risk neutral agents will buy lottery tickets when they believe that the lottery is being used to finance public goods which they value (Morgan and Sefton, 2000) and

\footnotetext{
${ }^{1}$ Grote and Matheson (2011) and Perez and Humphreys (2013) provide excellent surveys of the literature which helped us write this review.
} 
that the skewness of returns can explain engagement (Golec and Tamarkin, 1998; Garrett and Sobel, 1999; Walker and Young, 2001).

An extensive empirical literature investigates how demand for lotteries responds to factors such as the expected return on playing (so-called 'effective price models'), disposable income and other features of game design such as how many numbers can be chosen, and from what total, the number of prize classes, the size of jackpots and how frequently they are likely to occur (so-called 'jackpot' models) and the higher moments of the prize distribution (so-called 'higher moments' models). These address a range of policy questions, such as whether empirical evidence suggests that the lottery is revenue-maximising, its degree of regressivity and how it may be redesigned to arrest a long-term decline in sales, as happened with the U.K.'s National Lottery following its launch (Scoggins, 1995).

In the effective price model literature, Walker (1998) suggests that lotteries face a near-zero marginal cost of production and should be considered to be revenue maximisers, setting their optimal take-out rate as close as possible to the point at which the price elasticity of demand is equal to -1 . Using data from the U.K. National Lottery, they estimated the price elasticity to be very close to this, at -1.06, a finding supported by Forrest et al. (2000) and Farrell et al. (2000). Farrell and Walker (1999), using pooled cross-sectional data from the U.K. National Lottery, estimated price and income elasticities of demand of -1.456 and 0.132 , respectively. They note that their estimated price elasticity is close to the value of -1.55 which was previously estimated by Farrell et al. (1997) using time series data. Based on the estimate of the price elasticity of demand, they concluded that the U.K. National Lottery was not maximising revenue; based on the estimate of the income elasticity of demand, they concluded that the lottery was regressive. Using U.K. National Lottery data from 1997 to 2013, Wheeler (2018) estimated the price elasticity of demand to be -0.636 for Saturday draws and -1.472 for Wednesday draws. He concluded that the effective price of the game should be raised on Saturdays, to 0.77, and reduced on Wednesdays, to 0.362 .

Forrest et al. (2002) compared results from the traditional effective price model with those of the jackpot model and found long-run price elasticity estimates of -0.88 and -1.04 in the UK National Lottery Saturday and Wednesday draws, respectively, neither of which were statistically significantly different from -1 . They found that their jackpot model fitted the data better and they found strongly significant associations between jackpot size and sales. DeBoer (1990), Shapira and Venezia (1992), Scott and Gulley (1995), Matheson and Grob (2001) and Garrett and Sobel (2004) also estimated jackpot models of lottery demand. García and Rodríguez (2007) proposed a model of football pools in which both the expected return and the jackpot size are included as explanatory variables.

In the higher moments model of Walker and Young (2001), demand is modelled as a function of the probability distribution of prizes, accounting for the expected value, variance and skewness of the prize distribution. Walker and Young (2001) found a positive association between lottery sales and the expected return and skewness and a negative association between sales and variance. Recent work by Baker et al. (2019) uses the idea that lottery players have rational expectations over the expected level of sales in making their best guesses of the moments of the prize distribution. Using data from Spain's El Gordo lottery, they find similar results to Walker and Young (2001). 
A large body of empirical work has studied the effect of lotteries on the income distribution. Perez and Humphreys (2013, Table 3) report the results of 16 empirical studies, the majority of which found that lotteries are regressive, assessed either by estimating the income elasticity of demand, the Suits index (Suits, 1977), or both. The regional dimension of the distributional impact of gambling has also been assessed using Canadian data (Kitchen and Powells, 1991) and more recently for Italian regions (Gandullia and Leporatti, 2018). In his analysis of the U.K. National Lottery, Wheeler (2018) estimates a range of values for the income elasticity of demand, from -1.4 to -0.7 , suggesting that the lottery is an inferior good.

Concluding their review, Perez and Humphreys (2013) argue that the empirical literature needs to 'move on' from the first generation demand studies and examine in more detail matters such as the prize structure, in addition to the effective price of participation, in explaining lottery demand. The authors judge that none of the three main empirical models that they review effective price, jackpot and higher moments - has shown itself to be the preferred approach to modelling the demand for lotto.

The closest theoretical contribution to ours is that of Maeda (2008), who presents a model of optimal lottery design for an operator selling to a population of homogeneous individuals whose utility functions are additively separable in the utility of expenditure on the lottery and net expenditure on other goods. Utility of lottery participation is a function of the level of prize money and the probability of winning. Maeda studies two lottery models: a 'fixed prize' design, in which players buy tickets to win a single class of prize such that, the more tickets that a player buys, the greater their chances of winning; a 'fixed probability' ('pari-mutuel') design, in which a proportion of the total pool of revenue staked is offered as prize money. Maeda extends the basic models, which have a single class of prize, to the case of multiple classes.

Maeda's utility function is quasi-linear, with utility from lottery participation modelled as a Cobb-Douglas-type function showing diminishing returns to the probability of winning and the size of the prize pool. The quasi-linear nature of utility means that individual income does not influence demand. Maeda models the design as a two-stage game, in which the operator acts as a leader and the players follow. For the fixed prize design, the optimality condition defines the optimal level of the prize as a function of the total number of participants and the elasticities of ticket purchases with respect to the probability of winning and the size of the prize. For the fixed probability design, the optimal ratio of prize money to sales revenue is equal to the elasticity of ticket purchases with respect to the prize that is offered. In Maeda's multiple prize classes model, the revenue-maximising rule for lottery design is that, for each prize class, the expected return to revenue ratio should equal the elasticity of ticket purchases with respect to the amount of the prize.

Few studies have developed a theory of optimal game design when gross lottery expenditure is regressive, proportional or progressive. A notable exception is Clotfelter and Cook (1987), who studied the 'implicit tax' that the lottery places on players, insofar as it raises public finances in the same way that indirect taxes do. They considered a state lottery to be a monopoly and discussed the problems of using measures such as consumer surplus to measure welfare effects. ${ }^{2}$ They found that a reduction in the proportion of gross lottery expenditure kept by the

\footnotetext{
${ }^{2}$ These include matters such as consumers being misinformed about true odds of winning, addiction and the
} 
operator would benefit the poor proportionately more than the rich. Referencing the work of Feldstein (1972), they suggest a rule for optimal lottery pricing which maximises a social welfare function given a revenue constraint. They assume that state revenues rely on the sale of two goods - the lottery and another - in which the rule that the ratio of optimal mark-ups be equal to the price ratio is adjusted by an index reflecting what the authors call the 'distributional characteristic' of the goods. This 'distributional characteristic' is a weighted average of the marginal social utilities, where the weights are the consumption shares of each household. Absent a social welfare function, this adjustment does not exist. Comparing data on the implicit tax of lotteries with the tax rates on alcohol and tobacco, Clotfelter and Cook (1987) conclude that the rates on the lottery are too high relative to those on alcohol and tobacco.

\section{Models of lottery power}

We consider the problem facing the operator of a lottery who is charged with maximising revenue for the public finances. Following Maeda (2008) and Conlisk (1993), amongst others, we use the entertainment value of the lottery to justify the existence of a demand function. The population of potential lottery players is heterogeneous, in that demand for the lottery is assumed to be a function of both income and the design of the lottery, which we take to comprise features of the game such as the proportion of gross expenditure that is returned to players, the size of the jackpot and the distribution of prizes. Following existing contributions to the literature (e.g. Walker (1998)), we assume that the marginal cost of operating the game is negligible enough to be ignored.

To reflect the three models of lottery demand that are described in the literature reviewed above, we model a range of choice variables for the operator. In our first model, which we call the 'effective price model', the operator chooses the effective long term price of the game. In our 'higher moments-jackpot models', the operator chooses the size of the jackpot prize, which can influence demand directly (the 'pure jackpot model') as well as indirectly, via the higher moments of the prize distribution (the 'pure higher moments model'). We develop a full set of results for the efficiency and equality implications of optimal lottery design for the effective price model and consider these empirically in section 4. For the latter two models, we state the efficiency results only, owing to the fact that consideration of a wider range of incentives offers the opportunity for different combinations of choice variables and effects.

\subsection{The effective price model}

In the effective price (EP) model, the operator's choice variable is the lottery's return to player proportion (RTPP), $\alpha_{\mathrm{EP}} \in(0,1)$, that is, the proportion of gross lottery expenditure that is returned to players in the long run. ${ }^{3}$ Market demand for the lottery is assumed to be a function

existence of negative externalities.

${ }^{3}$ By taking the long-run perspective, we ignore draw-by-draw variation in the RTPP which arises from the presence of rollovers. A rollover occurs when a prize in one draw is not won and so 'rolls over' to the next. $\alpha_{\mathrm{EP}}$ refers to the long-run RTPP, taking into account the presence of rollovers. As argued by Scott and Gulley (1995), our 
of both the lottery's 'effective price', equal to $1-\alpha_{\mathrm{EP}}$ and also known as the 'take-out rate', and disposable income, defined as the random variable $Y_{P}$. Pre-gambling disposable income has density $f_{Y_{P}}$ on support $\left[y_{P, \min }, y_{P, \max }\right], y_{P, \min }>0, y_{P, \max } \geq y_{P, \min }$, with expected value $\mu_{Y_{P}}$ and variance $\sigma_{Y_{P}}^{2}$.

The operator faces no threat of entry and may therefore exercise what we term 'lottery power' in choosing her RTPP. Let $\beta\left(\alpha_{\mathrm{EP}}, y_{P}\right) \in[0,1]$ be the proportion of disposable income $y_{P}$ that is spent on the lottery. $\beta$ is assumed to be continuous and at least twice differentiable in each of its arguments. We assume that, if nothing is returned to the players, nothing is spent $\left(\beta\left(0, y_{P}\right)=0\right.$ for all $\left.y_{P}\right)$ and, even with the most generous RTPP, in which all gross lottery expenditure is returned to players, not all income need be spent $\left(\beta\left(1, y_{P}\right) \leq 1\right.$ for all $\left.y_{P}\right)$. We also assume that $\beta$ is strictly increasing in the RTPP, that is, $\beta_{\alpha_{\mathrm{EP}}}>0$, and that it may be strictly increasing, constant or strictly decreasing in $y_{P}$.

At income $y_{P}$, the operator takes $y_{G}=\beta\left(\alpha_{\mathrm{EP}}, y_{P}\right)\left(1-\alpha_{\mathrm{EP}}\right) y_{P}$ from players, leaving them with post-gambling income $y_{P-G}=y_{P}\left[1-\beta\left(\alpha_{\mathrm{EP}}, y_{P}\right)\left(1-\alpha_{\mathrm{EP}}\right)\right]$. When we express the proportion of income spent on the lottery as a function of its effective price, $1-\alpha_{\mathrm{EP}}$, rather than the RTPP, we write the demand function as $\tilde{\beta}\left(1-\alpha_{\mathrm{EP}}, y_{P}\right)$ and consider this to be a rate of market demand such that, the lower the effective price (the higher the RTPP), the more 'generous' the operator and the higher the rate of demand $\left(\tilde{\beta}_{\left(1-\alpha_{\mathrm{EP}}\right)}<0\right)$. This property - higher demand at a lower effective price - is borne out by some of the empirical studies that were reviewed in section 2 (Farrell and Walker, 1999; Forrest et al., 2000; Farrell et al., 2000; Forrest et al., 2002; Frontier Economics, 2014; Wheeler, 2018).

In choosing a RTPP which maximises revenue $R^{\mathrm{EP}}$ from the game, the operator acts as a monopolist facing a zero marginal cost (Clotfelter and Cook, 1987). By being more generous that is, increasing the RTPP (and so reducing the effective price) - the operator increases demand. However, increasing the RTPP also increases the proportion of gross lottery expenditure that is paid out in prize money. Normalising the size of the population to 1, the operator seeks to balance these opposing forces by choosing a value of $\alpha_{\mathrm{EP}}$ which maximises:

$$
R^{\mathrm{EP}}\left(\beta\left(\alpha_{\mathrm{EP}}, y_{P}\right), \alpha_{\mathrm{EP}}\right)=\int_{y_{P, \text { min }}}^{y_{P, \text { max }}}\left[\beta\left(\alpha_{\mathrm{EP}}, y_{P}\right)\left(1-\alpha_{\mathrm{EP}}\right) y_{P}\right] f_{Y_{P}}\left(y_{P}\right) \mathrm{d} y_{P}
$$

Define such a choice as $\alpha_{\mathrm{EP}}^{*}$. An interior solution for $\alpha_{\mathrm{EP}}^{*}$ satisfies the necessary condition $\left.R_{\alpha_{\mathrm{EP}}}^{\mathrm{EP}}\right|_{\alpha_{\mathrm{EP}}^{*}} ^{*}=0$ and is sufficient when $\left.R_{\alpha_{\mathrm{EP}} \alpha_{\mathrm{EP}}}^{\mathrm{EP}}\right|_{\alpha_{\mathrm{EP}}^{*}} ^{*}<0$, a condition which is always satisfied when $\beta$ is linear in $\alpha_{\mathrm{EP}}$, which is what we assume in this paper.

\subsubsection{Optimal pricing in the EP model}

Under appropriate regularity conditions for the functional form of $\beta$ and the income distribution, ${ }^{4}$ the following results show that the operator's optimal choice of RTPP may be expressed implicitly as a function of the sensitivity of market demand to changes in both the effective price

approach is consistent with the idea that lottery players have rational expectations of the effective price, based on observation of previous sales, the prize distribution, the size of past rollovers and so on.

${ }^{4}$ Namely, either that we are able to express $\beta$ as an $n$th degree polynomial in $y_{P}$ or, if this is not possible, that appropriate regularity conditions (see e.g. Loistl (1976)) hold for $\beta$ and the probability distribution for $Y_{P}$. 
of the game and individual income, as well as the degree of inequality in the income distribution, all evaluated at $\mu_{Y_{P}}$. Proposition 1 expresses an optimal choice of $\alpha_{\mathrm{EP}}$ in terms of the demand function $\tilde{\beta}$ and effective price when demand is additively separable in price and disposable income and may be approximated by a third degree polynomial in income. Its proof also states the sufficiency condition for such a choice. Corollary 1 expresses the optimal choice in terms of $\beta$ and the RTPP and introduces the idea of lottery power. Proofs are contained in Appendix A.

Proposition 1 (Optimal effective price). Under the above assumptions for the demand function, the revenue-maximising lottery operator selects the optimal effective price, $1-\alpha_{E P}^{*}$, to satisfy the following modified Lerner index pricing rule:

$$
\begin{aligned}
& -1 \approx \frac{1}{\varepsilon_{\tilde{\beta}, 1-\alpha_{E P}}}\left[1+c^{2} \varepsilon_{\tilde{\beta}, y_{P}}\left(1+\frac{1}{2} \varepsilon_{\tilde{\beta}_{y_{P}}, y_{P}}\{1+\tilde{\Omega}\}\right)\right]_{y_{P}=\mu_{Y_{P}}, \alpha_{E P}^{*}}, \\
& \text { where } \tilde{\Omega} \approx c \gamma\left(1+\frac{1}{3} \varepsilon_{\tilde{\beta}_{y_{P} y_{P}}, y_{P}}\right),
\end{aligned}
$$

where $c=\sigma_{Y_{P}} / \mu_{Y_{P}}$ is the coefficient of variation of the income distribution, $\gamma$ is its skewness and $\varepsilon_{a, b}$ is the elasticity of a with respect to $b$ evaluated at $\left(\left(1-\alpha_{E P}^{*}\right), \mu_{Y_{P}}\right)$, so that $\varepsilon_{\tilde{\beta}, 1-\alpha_{E P}^{*}}=$ $\left[\partial \tilde{\beta} / \partial\left(1-\alpha_{E P}^{*}\right)\right]\left(\left(1-\alpha_{E P}^{*}\right) / \tilde{\beta}\right)$ is the effective price elasticity of demand at $\mu_{Y_{P}}$.

Corollary 1 (Lottery power in the EP model). The lottery operator choosing the effective price to satisfy Eq. (2) equates the effective fractional odds of winning with an index of the operator's 'lottery power', $\Upsilon_{E P}^{*}$, at $\mu_{Y_{P}}$ :

$$
\begin{aligned}
& \frac{1-\alpha_{E P}^{*}}{\alpha_{E P}^{*}} \approx \Upsilon_{E P}^{*}, \\
& \text { where } \Upsilon_{E P}^{*}=\frac{1}{\varepsilon_{\beta, \alpha}}\left[1+c^{2} \varepsilon_{\beta, y_{P}}\left(1+\frac{1}{2} \varepsilon_{\beta_{y_{P}}, y_{P}}\{1+\Omega\}\right)\right]_{y_{P}=\mu_{Y_{P}, \alpha_{E P}^{*}}} \\
& \text { and } \Omega=c \gamma\left(1+\frac{1}{3} \varepsilon_{\beta_{y_{P} y_{P}, y_{P}}}\right)
\end{aligned}
$$

Hence, the stronger (weaker) is the operator's lottery power (the higher (lower) is $\Upsilon_{E P}^{*}$ ), the higher (lower) are the optimal effective fractional odds and the less (more) generous is the operator.

Proposition 1 shows that, when the demand function for the lottery varies according to disposable income, the standard Lerner index rule for profit maximisation, $\varepsilon_{\tilde{\beta}, 1-\alpha_{\mathrm{EP}}}=-1$, must be adjusted by the term in square brackets on the RHS of Eq. (2). This accounts for the degree of inequality and skewness in the income distribution (as measured by $c$ and $\gamma$ ), together with terms which reflect the responsiveness of demand to changes in income, measured at mean disposable income. The expression may easily be extended to accommodate higher order polynomials, or restricted to deal with e.g. a quadratic function.

We can extend our analysis to consider how the presence of regressive/progressive gross lottery expenditure affects optimal pricing, relative to the case when gross lottery expenditure is proportional. 
Definition 1. Other things equal, for any non-degenerate income distribution and all demand functions $\tilde{\beta}$ :

$$
\begin{array}{r}
\text { gross lottery expenditure is regressive/proportional/progressive for all } y_{P} \Leftrightarrow \frac{\partial \tilde{\beta}}{\partial y_{P}} \lesseqgtr 0 \\
\text { for all } y_{P} \in\left[y_{P, \min }, y_{P, \max }\right] .
\end{array}
$$

Definition 2 (Proportional gross lottery expenditure and standard Lerner index rule pricing). For any non-degenerate income distribution, define $\hat{\alpha}_{E P}$ as the RTPP which solves Eq. (2) when $\tilde{\beta}$ is invariant to an individual's income (so that gross lottery expenditure is proportional). Define $\hat{\tilde{\beta}} \equiv \tilde{\beta}\left(0, y_{P}\right)$ for this scenario. Define $\hat{\Upsilon}_{E P}$ as the corresponding value of lottery power. Then $\varepsilon_{\tilde{\beta}, y_{P}}=0$ (by Definition 2) and $\varepsilon_{\tilde{\beta}, 1-\hat{\alpha}_{E P}}=-1$ (by Eq. (2)).

Proposition 2 (Optimal effective price when gross lottery expenditure is regressive/progressive relative to when it is proportional). Define $\alpha_{E P}^{*}$ as the optimal RTPP when gross lottery expenditure is regressive/progressive, such that $\tilde{\beta}$ passes through $\hat{\tilde{\beta}}\left(0, \mu_{Y_{P}}\right)$ as defined in Definition 2. Then:

$$
\frac{\partial \tilde{\beta}}{\partial y_{P}} \lessgtr 0 \Leftrightarrow \alpha_{E P}^{*} \gtrless \hat{\alpha}_{E P} \Leftrightarrow \Upsilon_{E P}^{*} \lessgtr \hat{\Upsilon}_{E P}
$$

The intuition behind these results may be explained by consulting Figure 1. The shaded surface shows a demand function $\tilde{\beta}$ plotted in $\left(1-\alpha_{\mathrm{EP}}\right) \times y_{P} \times \tilde{\beta}$ space for the case of regressive gross lottery expenditure. Three linear demand functions which hold $y_{P}$ constant and show how $\tilde{\beta}$ varies with effective price are indicated by thick lines, one at $y_{P, \min }$, one at $y_{P, \max }$ and one at $\mu_{Y_{P}}$ (labelled $A$ ).

Consider first the case of a degenerate income distribution (so that $c=0$ ), with all potential players having disposable income equal to $\mu_{Y_{P}}$. As is clear from inspection of Eq. (2), the standard Lerner index pricing rule applies: revenue is maximised by setting the effective price to the point on demand function $A$ at which the price elasticity of demand (indicated by $\hat{\varepsilon}$ in Figure 1) is equal to -1. Define $\hat{\alpha}_{\mathrm{EP}}$ as the optimal choice of RTPP for this scenario. For the case of a nondegenerate income distribution, when gross lottery expenditure is proportional, so that $\tilde{\beta}$ is does not change with income and passes through $\mu_{Y_{P}}$ when effective price is equal to zero, the optimal RTPP is again equal to $\hat{\alpha}_{\mathrm{EP}}$. This result is clear from inspection of Eq. (2), this time setting $\varepsilon_{\tilde{\beta}, y_{P}}=0$.

Now consider Proposition 1, and the impact of regressive gross lottery expenditure on the optimal choice of $\alpha_{\mathrm{EP}}$, such that $\tilde{\beta}=\hat{\tilde{\beta}}$ when price is equal to zero and $y_{P}=\mu_{Y_{P}}$. When gross lottery expenditure is regressive, $\varepsilon_{\tilde{\beta}, y_{P}}<0$ by Definition 2 , and the term in square brackets on the RHS of Eq. (2) lies between zero and one. Hence, for Eq. (2) to hold, the absolute value of $\varepsilon_{\tilde{\beta},\left(1-\alpha_{\mathrm{EP}}\right)}$ must fall, meaning that effective price must also fall. Eq. (2) shows that the operator lowers effective price below $1-\hat{\alpha}_{\mathrm{EP}}$, being more generous in its choice of RTPP. The marginal reduction in the revenue earned from the players is more than offset by the increase in revenue that a reduction in price brings. From Eq. (3), the odds fall and the operator's lottery power 


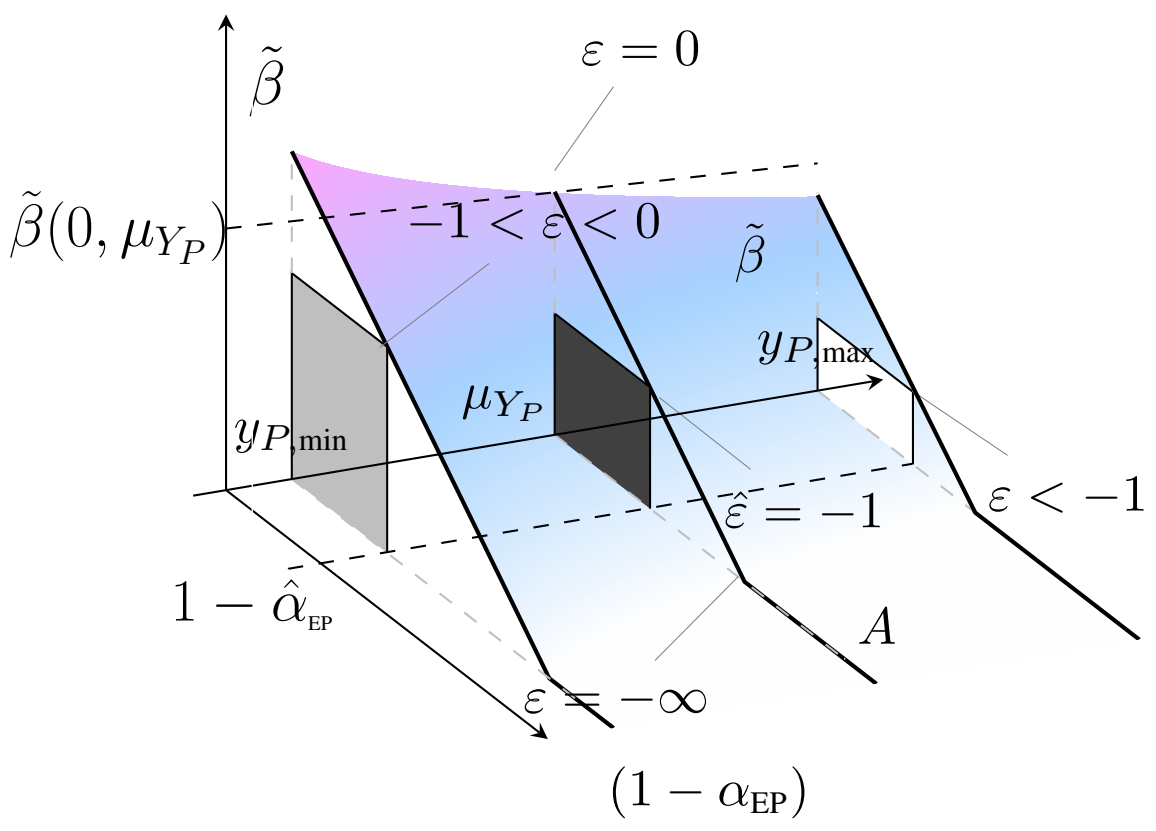

Figure 1: Market demand function and optimal effective pricing when gross lottery expenditure is regressive

is lower. Similar reasoning may be used to show that, for the case of progressive gross lottery expenditure, the operator sets a lower RTPP (a higher effective price), higher odds and so has higher lottery power.

To the best of our knowledge, these results are new to the literature on optimal lottery design. We note that the empirical literature that was reviewed in section 2 considers the revenuemaximising RTPP to be $\hat{\alpha}_{\mathrm{EP}}$ as defined in Definition 2, the value of the RTPP which satisfies the standard Lerner index pricing rule. Proposition 1 makes clear that $\hat{\alpha}_{\mathrm{EP}}$ is only optimal for the case of proportional gross lottery expenditure and that $\alpha_{\mathrm{EP}}^{*}$ deviates from this choice under regressive or progressive gross lottery expenditure. In considering optimal effective pricing, the empirical literature does not take this regressivity/progressivity result into account, possibly because empirical models have traditionally separated the estimation of price effects from those of income effects.

\subsubsection{Implications for the distribution of post-gambling income in the EP model}

The discussion to date has considered the impact of regressive, proportional and progressive gross lottery expenditure on optimal effective pricing. Consider now the distributional implications of our results for the gambling income $Y_{G}$ that is taken by the operator (i.e. that is lost by the players). We borrow results from the taxation literature on the liability progression index (Lambert, 2001; Jakobsson, 1976), which in our context is:

$$
\ell\left(\alpha_{\mathrm{EP}}, y_{P}\right)=\varepsilon_{y_{G}, y_{P}}=\varepsilon_{\tilde{\beta}, y_{P}}+1 .
$$


Applying Jakobsson (1976, Proposition 3) to our setting, we can state the following results.

Proposition 3 (Redistributive effect of pricing under regressive / neutral / progressive gross lottery expenditure). Independently of the chosen value of $\alpha_{E P}$, gambling revenue is regressive when $\partial \tilde{\beta} / \partial y_{P}<0$ for all $y_{P}$, it is neutral when $\partial \tilde{\beta} / \partial y_{P}=0$ for all $y_{P}$ and it is progressive when $\partial \tilde{\beta} / \partial y_{P}>0$ for all $y_{P}$.

Note that the result in Proposition 3 differs from the standard result in the direct taxation literature owing to the function $\tilde{\beta}$ in the definition of $y_{G}$ : in the direct taxation literature a fixed tax rate is always distributionally neutral.

We now use a result from Lambert (2001, Lemma 8.1) to set up our discussion of the equality implications of the various pricing rules.

Result 1 (Lambert (2001)). Let $m\left(y_{P}\right)$ and $n\left(y_{P}\right)$ be two functions of $y_{P}$. The concentration curve for $m$ with respect to $y_{P}$ lies nowhere below the concentration curve for $n$ if and only if $\varepsilon_{m, y_{P}} \leq \varepsilon_{n, y_{P}}$ for all $y_{P}$.

From this, we can state the following result for optimal lottery pricing as defined in Proposition 1 relative to pricing which follows the standard Lerner index rule.

Proposition 4 (Implications of optimal lottery pricing for the redistribution of income). Let $Y_{G}^{*}$ be the revenue taken from players when $\alpha=\alpha_{E P}^{*}$ (as defined in Proposition 1). Let $\hat{Y}_{G}$ be the revenue taken from players when $\alpha=\hat{\alpha}_{E P}$ (as defined in Definition 2). Then, regardless of whether $\alpha_{E P}^{*}>\hat{\alpha}_{E P}$ or $\alpha_{E P}^{*}<\hat{\alpha}_{E P}, \varepsilon_{y_{G}, y_{P}}^{*}>\hat{\varepsilon}_{y_{G}, y_{P}}$ for all $y_{P} \in\left[y_{P, \min }, y_{P, \max }\right]$ and $Y_{G}^{*}$ is Lorenzdominated by $\hat{Y}_{G}$.

We note that, in the context of our model, if one distribution of $Y_{G}$ Lorenz dominates another, that distribution is more regressive, when viewed from the perspective of the concentration curve. Hence, under the standard Lerner index pricing rule, any cumulative proportion of the population ranked lowest to highest according to disposable income loses proportionally more on the lottery than does the same cumulative proportion under optimal pricing.

To conclude the analysis of the EP model, we note that the above results are amplified by the degree of inequality in disposable income.

Corollary 2 (Comparative statics for inequality in disposable income). Other things being equal, the greater the degree of relative inequality in disposable income, $c$, the greater is $\left|\alpha_{E P}^{*}-\hat{\alpha}_{E P}\right|$.

\subsection{The jackpot and higher moments models}

In the jackpot and higher moments models, we assume there exists a prize distribution which comprises smaller prizes together with a jackpot, $J$. Market demand $\beta$ is assumed to be a function of $J$ relative to the value of the smaller prizes (which we assume are fixed), such that the proportion of spend is increasing in $J$ but at a decreasing rate $\left(\partial \beta / \partial J>0\right.$ and $\left.\partial^{2} \beta / \partial J^{2}<0\right)$. The 'pure jackpot model' posits a direct causal effect of $J$ on demand. The 'higher moments 
model' posits an indirect causal effect of $J$ operating via the higher moments of the prize distribution, which we call $\phi$. We solve the two models as one, so that the pure versions are special cases of the general. We do so for the case of a second degree polynomial function linking $\beta$ to $y_{P}$, noting that it is straightforward to extend the analysis for polynomials of higher order, using the methods presented in section 3.1.5

The operator faces the problem of choosing a jackpot, $J$, to maximise:

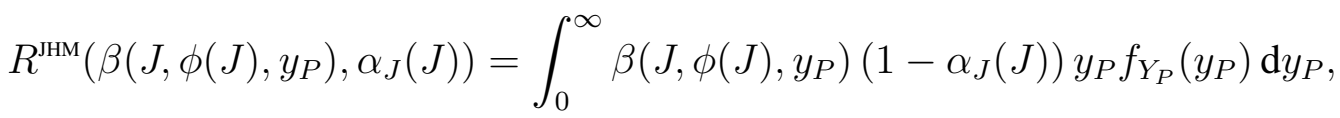

where $\partial \alpha_{J} / \partial J>0$. Define $J^{*}$ as a solution to this problem and define $\alpha_{J}^{*} \equiv \alpha_{J}^{*}\left(J^{*}\right)$ as the corresponding RTPP. Subject to the appropriate regularity conditions for the income distribution and $\beta$, proceeding as before leads to the following results.

Proposition 5 (Optimal jackpot size in the jackpot and higher moments models). When $\beta$ is additively separable in $J, \phi$ and $y_{P}$, the revenue-maximising operator selects the optimal jackpot size, $J^{*}$, to satisfy the following modified Lerner index pricing rule:

$$
-1 \approx \frac{\varepsilon_{1-\alpha_{J}, J}}{\eta_{\beta, J}}\left[1+c^{2} \varepsilon_{\beta, y_{P}}\left(1+\frac{1}{2} \varepsilon_{\beta_{y_{P}}, y_{P}}\{1+\Omega\}\right)\right]_{y_{P}=\mu_{Y_{P}}, J^{*}},
$$

where $\eta_{\beta, J}=\left[\varepsilon_{\beta, J}+\beta_{\phi} \phi_{J}\right](J / \beta)$ is the elasticity of $\beta$ with respect to $J$, operating directly on $\beta$ and indirectly via $\phi$. Setting $\beta_{\phi}=0$ yields the pure jackpot model and setting $\varepsilon_{\beta, J}=0$ yields the pure higher moments model.

Corollary 3 (Lottery power in the jackpot and higher moments models). The lottery operator choosing $J^{*}$ to satisfy Eq. (6) equates the effective fractional odds of winning with the index of the operator's lottery power, $\Upsilon_{J}^{*}$, at mean disposable income:

$$
\begin{aligned}
\frac{1-\alpha_{J}\left(J^{*}\right)}{\alpha_{J}\left(J^{*}\right)} & \approx \Upsilon_{J}^{*}, \\
\text { where } \Upsilon_{J}^{*} & =\frac{\varepsilon_{\alpha_{J}, J}}{\eta_{\beta, J}}\left[1+c^{2} \varepsilon_{\beta, y_{P}}\left(1+\frac{1}{2} \varepsilon_{\beta_{y_{P}}, y_{P}}\{1+\Omega\}\right)\right]_{y_{P}=\mu_{Y_{P}}, J^{*}} .
\end{aligned}
$$

The mechanism driving the optimal size of the jackpot is similar to that in the EP model. However, in these models, the choice variable $J$ affects both the RTPP and demand. When the distribution of income is degenerate $(c=0)$, or $\partial \beta / \partial J=0$, Eq. (6) shows that the optimal choice of $J$ satisfies $\varepsilon_{1-\alpha_{J}, J}=-\eta_{\beta, J}$. The operator balances the revenue-increasing effect that increasing $J$ has on raising marginal willingness to pay with the revenue-diminishing effect that it has on the effective price.

For the pure jackpot model, the analysis of section 3.1 may be applied once more to obtain the following proposition.

\footnotetext{
${ }^{5}$ More sophisticated models could be solved. For example, an alternative specification would be one in which increasing $J$ may only be achieved by reducing the size of the smaller prizes. Another option would be explicit modelling of demand as a function of the higher moments of the prize distribution, such as the variance and skewness.
} 
Proposition 6 (Optimal jackpot size with regressive/progressive gross lottery expenditure). For any non-degenerate income distribution, define $\hat{J}$ as the optimal size of the jackpot when lottery participation is invariant to an individual's income and define $J^{*}$ as the optimal size of the jackpot when it is not. Then, for all market demand functions $\beta$ which are additively separable in $y_{P}$ and $\left(1-\alpha_{J}(J)\right)$ :

$$
\begin{array}{r}
\text { Lottery participation is regressive/progressive for all } y_{P} \Leftrightarrow \\
\qquad J^{*} \gtrless \hat{J} \Leftrightarrow \Upsilon_{J}^{*} \lessgtr \hat{\Upsilon}_{J} .
\end{array}
$$

For the pure higher moments model and the mixed jackpot/higher moments models, results depend on the net effect of changes in the higher moments of the prize distribution relative to the direct effect of $J$ on demand.

\section{Does the U.K. National Lottery exploit its lottery power?}

We apply the effective price model solved in section 3.1 using data from the U.K. National Lottery's Saturday game between 1997 and 2013 and compare the efficiency and equality implications of the actual, long-term, RTPP of the game with the revenue-maximising RTPP suggested by our model (Proposition 1) and with the RTPP given by the standard Lerner index rule (Definition 2). We use results from the series of essays presented by Wheeler (2018), who estimated price and income elasticities of demand for the U.K. National Lottery's Saturday and Wednesday games. Appendix B presents full details of the calculations used in our analysis; below we provide an overview of our methods and discuss the main results.

The slope of the demand function, $\partial \tilde{\beta} / \partial\left(1-\alpha_{\mathrm{EP}}\right)$, is estimated using Wheeler's results for the National Lottery's Saturday game between 5 February 1997 and 2 October 2013 (Wheeler, 2018, Chapter 3). The parameters of the income distribution are obtained by fitting a truncated lognormal distribution to data plotted from Wheeler's analysis of expenditure data (taken as a proxy for disposable income) from the U.K. Expenditure and Food Survey (EFS) (Wheeler, 2018, Figure 4.7), covering the period 2001 to 2013. A quadratic functional form is assumed for $\tilde{\beta}\left(y_{P}\right)$ and parameters for it are estimated from Wheeler (2018, Figure 4.7), which plots the proportion of spend on the lottery as a function of disposable income. Results of the analysis of fitting $\tilde{\beta}$ to disposable income and fitting the truncated normal distribution to the income distribution are presented in Figures 2 (a) and (b). ${ }^{6}$

\subsection{Results}

We obtain an optimal RTPP for the U.K.'s Saturday game of $\alpha_{\mathrm{EP}}^{*}=0.408$. This is about ten percentage points less generous than the game's actual RTPP over the period in question $\left(\alpha_{\mathrm{EP}}=0.514\right)$. The RTPP suggested by the standard Lerner index rule is $\hat{\alpha}_{\mathrm{EP}}=0.236$, which is in accord with the optimal effective price of 0.77 suggested by Wheeler (2018). However,

\footnotetext{
${ }^{6}$ Analysis is carried out using Maple 2017 and Matlab R2018a.
} 
this standard Lerner index rule omits the role of the income distribution and the function relating lottery spend to disposable income in determining the optimal RTPP. The net result is that the standard Lerner index RTPP is seventeen percentage points below the revenue-maximising RTPP. Figure 2(c) shows how, as the RTPP falls (the effective price of the game rises), the proportion of disposable income spent on the lottery falls across the income distribution. Figure 2(d) shows how expected revenue changes as the RTPP changes. Comparison of the optimal value of expected revenue with that under the actual RTPP suggests that switching from the actual RTPP to the optimal one would increase the operator's revenue by about $3.4 \%$. Revenue is about $9 \%$ higher under the optimal RTPP than under standard Lerner index pricing. Considered in terms of the operator's average take from the Saturday game for a non-rollover draw (Wheeler, 2018, Table 3.1), this suggests the operator could have increased the average revenue from non-rollover Saturday games from about $£ 19.8 \mathrm{~m}$ to $£ 20.5 \mathrm{~m}$ (an increase of around $£ 700,000$ ). If the operator were instead to have priced according to the standard Lerner index rule, revenue per game would have fallen by about $£ 1.24 \mathrm{~m}$ to $£ 19.7 \mathrm{~m}$, which would be about $£ 2.0 \mathrm{~m}$ short of the maximum. So the answer to the question 'Does the U.K. National Lottery exploit its lottery power?', insofar as it relates to revenue-maximisation, is 'not quite': the operator could have increased revenue by a small amount (3.4\%) if it had been less generous in its choice of RTPP.

Consider now Figure 3, which shows the distributional implications of the three RTPPs. Figure 3(a) shows that, under the actual RTPP and $\alpha_{\mathrm{EP}}^{*}$, gambling revenue is an increasing and concave function of weekly disposable income. However, it is increasing and then decreasing in weekly disposable income under the standard Lerner index rule. Figure 3(b) shows that the elasticity of $y_{G}$ with respect to $y_{P}$ is highest under the actual RTPP and lowest under $\hat{\alpha}_{\mathrm{EP}}$, with the elasticity for $\alpha_{\mathrm{EP}}^{*}$ lying between the two. By Result 1, this implies that the concentration curve for $\hat{\alpha}_{\mathrm{EP}}$ dominates that for $\alpha_{\mathrm{EP}}^{*}$, which in turn dominates that for the actual RTPP, a result which is confirmed by the concentration curves that are plotted in Figure 3(d). Furthermore, Figure 3(b) confirms the result of Proposition 4: the elasticity of $y_{G}$ with respect to $y_{P}$ at $\alpha_{\mathrm{EP}}^{*}$ is strictly greater than the elasticity of $y_{G}$ with respect to $y_{P}$ at $\hat{\alpha}_{\mathrm{EP}}$, so that $Y_{G}^{*}$ is Lorenz-dominated by $\hat{Y}_{G}$. Finally, note that Lorenz dominance in the distribution of $Y_{G}$ under the three RTPPs may be interpreted in terms of the regressivity in the revenue earned by the operator. Figure 3(c) shows that the proportion of gambling revenue taken from the poor is highest under standard Lerner index pricing, and also falls most rapidly as income increases. The proportion taken from the poor is next highest under optimal pricing and remains so until weekly disposable income is around $£ 800.00$. So the most progressive RTPP is under actual pricing.

The upshot of this analysis is that our results suggest that the U.K. National Lottery operator was not fully exploiting its monopoly power over the period in question, and so was losing out on a relatively small amount of revenue in non-rollover Saturday games. However, the operator was also setting the least regressive RTPP of the three that are under consideration. It may be argued therefore, that its choice of RTPP was broadly in line with its obligations as laid out in the National Lottery Act 1993, namely that the Secretary of State should 'do his best to ensure that the net proceeds of the National Lottery are as great as possible', while at the same time protecting the participants in the lottery. Protecting participants means not designing games which 'encourage excessive play or target particular groups.' 


\section{Discussion and conclusion}

Although there exists an extensive empirical literature assessing the optimal design of state lotteries, there is more limited theoretical assessment of the factors which affect revenue maximisation. We have presented a range of models for a lottery operator who is charged with raising revenue for the public finances, in which demand is a function of both disposable income and the pricing of the game. In a departure from the current literature, which applies standard monopoly theory to assess whether or not an operator is acting efficiently by maximising revenue, we show that optimal lottery pricing should account for corrections for the degree of inequality and skewness in the income distribution and features of the function relating lottery spend to disposable income. In particular, when gross lottery expenditure is regressive, it is optimal for the operator to improve the terms of the game by being more generous with the proportion of spend that is returned to players; when gross lottery expenditure is progressive, the operator should be less generous. Compared with our optimal rule, standard Lerner index pricing is neither efficient, nor is it the most equitable.

Our application has used results from analysis of the U.K. National Lottery's Saturday game between 1997 and 2013 to show that the effective price was about ten percentage points too low to be efficient, so that the operator was not fully exploiting its lottery power. However, the application has also shown that, were it to have raised the effective price of the game to improve efficiency, it would also have increased inequality.

There are numerous directions for future research. The theoretical model could be improved

by solving a model in which $\tilde{\beta}$ is non-separable in disposable income and price, and more work could be done to tease out the distributional implications of optimal pricing in the pure jackpot and higher moments models. Further, it would be interesting to exploit other country-level data on lottery spend and participation, with a view to assessing the degree to which operators place efficiency considerations above those of inequality.

\section{A Proofs}

Proof of Proposition 1. The first order necessary condition for an interior solution which results from solving the optimisation problem for the effective price model is:

$$
\left(1-\alpha_{\mathrm{EP}}^{*}\right) \int_{y_{P, \text { min }}}^{y_{P, \text { max }}} \beta_{1}\left(\alpha_{\mathrm{EP}}^{*}, y_{P}\right) y_{P} f_{Y_{P}}\left(y_{P}\right) \mathrm{d} y_{P}=\int_{y_{P, \min }}^{y_{P, \max }} \beta\left(\alpha_{\mathrm{EP}}^{*}, y_{P}\right) y_{P} f_{Y_{P}}\left(y_{P}\right) \mathrm{d} y_{P},
$$

where $\beta_{1}\left(\alpha_{\mathrm{EP}}^{*}, y_{P}\right)=\partial \beta\left(\alpha_{\mathrm{EP}}^{*}, y_{P}\right) / \partial \alpha_{\mathrm{EP}}$. The condition is sufficient when:

$$
R_{\alpha_{\mathrm{EP}} \alpha_{\mathrm{EP}}}^{\mathrm{EP}}=\int_{0}^{\infty}\left[\beta_{11}\left(\alpha_{\mathrm{EP}}^{*}, y_{P}\right)\left(1-\alpha_{\mathrm{EP}}^{*}\right)-2 \beta_{1}\left(\alpha_{\mathrm{EP}}^{*}, y_{P}\right)\right] y_{P} f_{Y_{P}}\left(y_{P}\right) \mathrm{d} y_{P}<0,
$$

where $\beta_{11}\left(\alpha_{\mathrm{EP}}^{*}, y_{P}\right)=\partial^{2} \beta\left(\alpha_{\mathrm{EP}}^{*}, y_{\vec{P}}\right) / \partial \alpha_{\mathrm{EP}}^{2}$. This condition always hold at interior values of the RTPP given our assumption that $\tilde{\beta}$ is linear in effective price. 

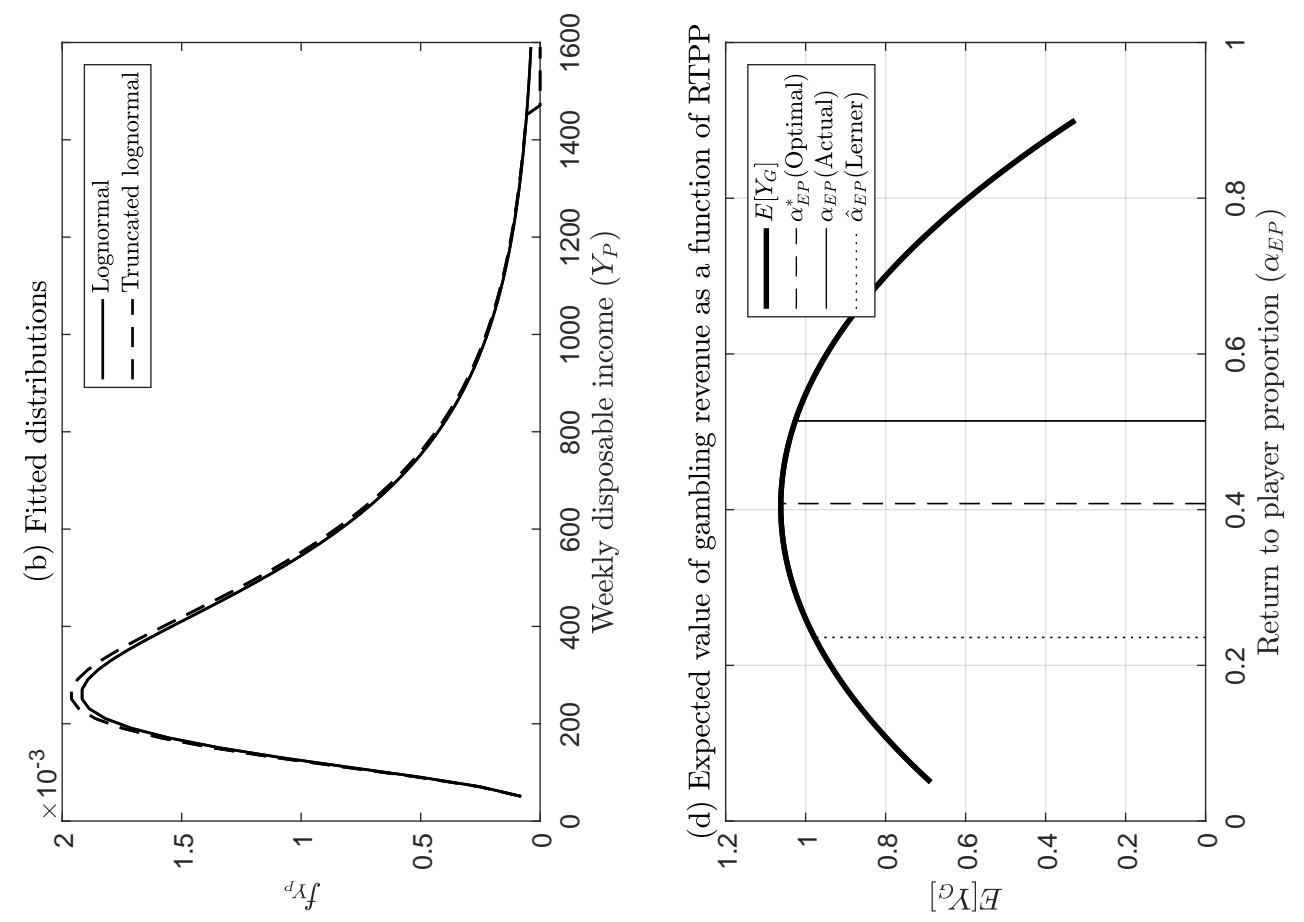

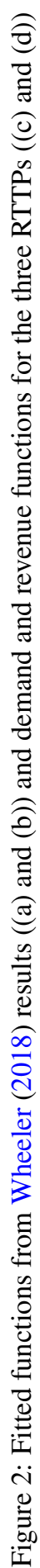



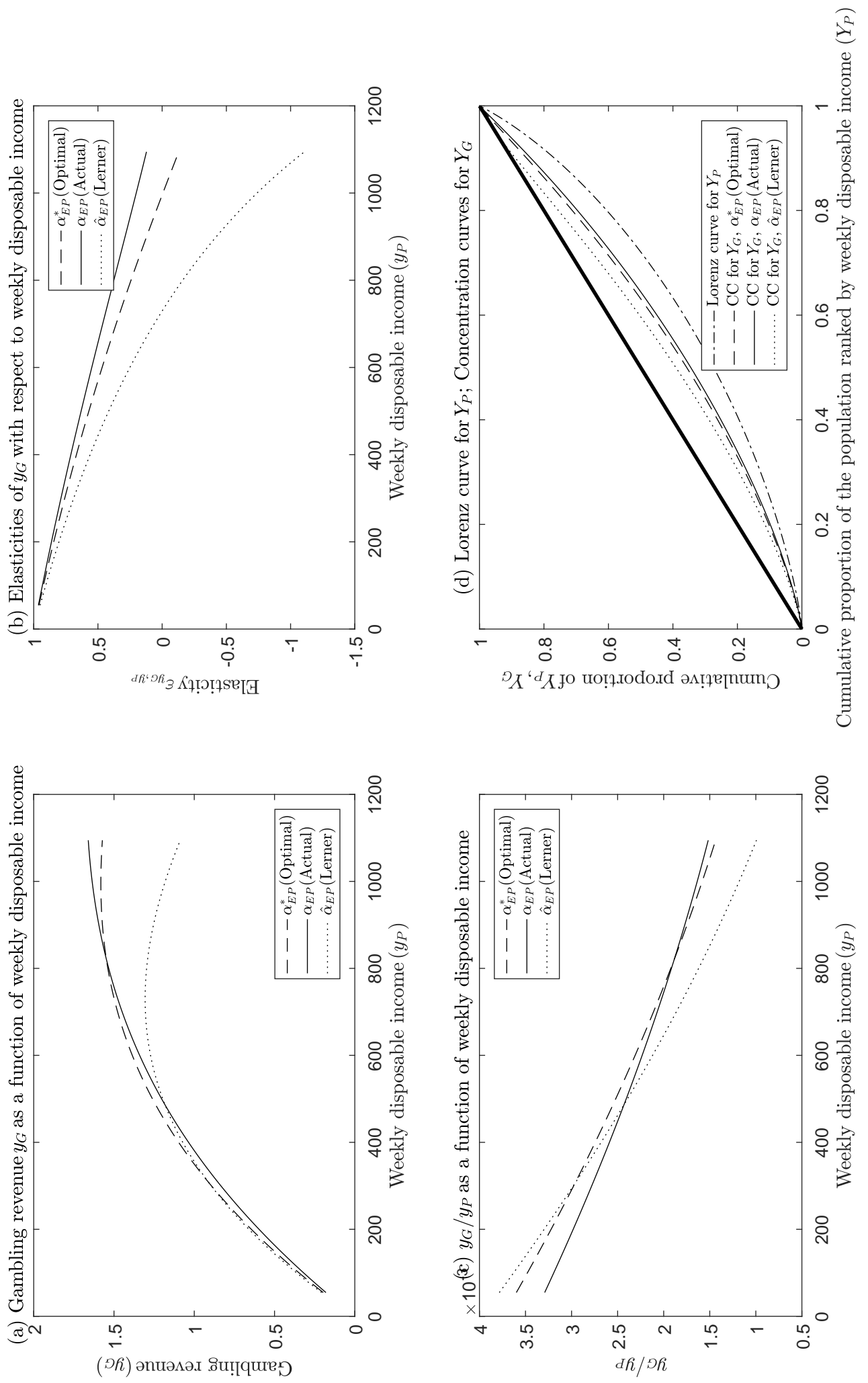

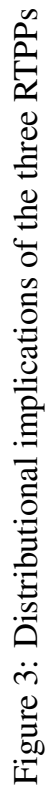


Using Taylor series expansions for the two expected values in Eq. (9),

$$
\begin{aligned}
\mathbb{E}\left[\beta_{1}\left(\alpha_{\mathrm{EP}}^{*}, y_{P}\right) y_{P}\right] & =\beta_{1}\left(\alpha_{\mathrm{EP}}^{*}, \mu_{Y_{P}}\right) \mu_{Y_{P}}+\frac{\sigma_{Y_{P}}^{2}}{2}\left[\frac{\partial^{3} \beta\left(\alpha_{\mathrm{EP}}^{*}, \mu_{Y_{P}}\right)}{\partial \alpha_{\mathrm{EP}} \partial y_{P}^{2}} \mu_{Y_{P}}+2 \frac{\partial^{2} \beta\left(\alpha_{\mathrm{EP}}^{*}, \mu_{Y_{P}}\right)}{\partial \alpha_{\mathrm{EP}} \partial y_{P}}\right] \\
\text { +h.o.t. } & \\
\mathbb{E}\left[\beta\left(\alpha_{\mathrm{EP}}^{*}, y_{P}\right) y_{P}\right] & =\beta\left(\alpha_{\mathrm{EP}}^{*}, \mu_{Y_{P}}\right) \mu_{Y_{P}}+\frac{\sigma_{Y_{P}}^{2}}{2}\left[\frac{\partial^{2} \beta\left(\alpha_{\mathrm{EP}}^{*}, \mu_{Y_{P}}\right)}{\partial y_{P}^{2}} \mu_{Y_{P}}+2 \frac{\partial \beta\left(\alpha_{\mathrm{EP}}^{*}, \mu_{Y_{P}}\right)}{\partial y_{P}}+\right. \\
& \left.\frac{\sigma_{Y_{P}} \gamma}{3}\left(\frac{\partial^{3} \beta}{\partial y_{P}^{3}} \mu_{Y_{P}}+3 \frac{\partial^{2} \beta}{\partial y_{P}^{2}}\right)\right]+ \text { h.o.t. }
\end{aligned}
$$

These may be expanded to higher orders according to the characteristics of $\tilde{\beta}$ and the distribution of income. For the results in section 3.1, we work with a polynomial of degree 3 for $\tilde{\beta}$ and a lognormal distribution for $Y_{P}$ and hence use expansions to the third order. When $\beta$ is additively separable in $y_{P}$ and $\alpha_{\mathrm{EP}}$, the cross-partial derivatives in these expressions may be ignored. Substituting Eqs. (11a) and (11b) into Eq. (9), simplifying, and noting that the effective price elasticity of demand and the elasticity of demand with respect to the RTPP are related as follows: $\varepsilon_{\tilde{\beta}, 1-\alpha_{\mathrm{EP}}}=\varepsilon_{\beta, \alpha_{\mathrm{EP}}}\left(-\left(1-\alpha_{\mathrm{EP}}\right) / \alpha_{\mathrm{EP}}\right)$, gives Eq. (2).

Proof of Corollary 1. Replacing $\varepsilon_{\tilde{\beta}, 1-\alpha_{\mathrm{EP}}}$ with $\left(-\left(1-\alpha_{\mathrm{EP}}\right) / \alpha_{\mathrm{EP}}\right) \varepsilon_{\beta, \alpha_{\mathrm{EP}}}$ in Eq. (2) gives Eq. (3).

Proof of Proposition 2. If: when gross lottery expenditure is regressive, $\varepsilon_{\tilde{\beta}, y_{P}}<0$ and so, since $\varepsilon_{\tilde{\beta}, 1-\alpha_{\mathrm{EP}}}<0$, from Eq. (2):

$$
\left[1+c^{2} \varepsilon_{\tilde{\beta}, y_{P}}\left(1+\frac{1}{2} \varepsilon_{\tilde{\beta}_{y_{P}}, y_{P}}\left\{1+c \gamma\left(1+\frac{1}{3} \varepsilon_{\tilde{\beta}_{y_{P} y_{P}, y_{P}}}\right)\right\}\right)\right]_{y_{P}=\mu_{Y_{P}}, \alpha_{\mathrm{EP}}^{*}}>0
$$

But from Eq. (11b), it is the case that:

$$
0<\left[c^{2} \varepsilon_{\tilde{\beta}, y_{P}}\left(1+\frac{1}{2} \varepsilon_{\tilde{\beta}_{y_{P}}, y_{P}}\left\{1+c \gamma\left(1+\frac{1}{3} \varepsilon_{\tilde{\beta}_{y_{P} y_{P}, y_{P}}}\right)\right\}\right)\right]_{y_{P}=\mu_{Y_{P}}, \alpha_{\mathrm{EP}}^{*}}<1,
$$

Hence, for Eq. (2) to hold, $\left|\varepsilon_{\tilde{\beta}, 1-\alpha_{\mathrm{EP}}}\right|<1$ and so $\alpha_{\mathrm{EP}}^{*}>\hat{\alpha}_{\mathrm{EP}}$. Substituting $\alpha_{\mathrm{EP}}^{*}$ into the LHS of Eq. (3) shows that the fractional odds fall and $\Upsilon_{\mathrm{EP}}^{*}<\hat{\Upsilon}_{\mathrm{EP}}$. Only if: when $\Upsilon_{\mathrm{EP}}^{*}<\hat{\Upsilon}_{\mathrm{EP}}$, it must be the case that $\alpha_{\mathrm{EP}}^{*}>\hat{\alpha}_{\mathrm{EP}}$ (by Eq. (3)) and so, from Eq. (2), $\left|\varepsilon_{\tilde{\beta}, 1-\alpha_{\mathrm{EP}}}\right|<1$. By Eq. (2) and Eq. (11b) this can only be the case if $\varepsilon_{\tilde{\beta}, y_{P}}<0$.

Similar reasoning may be applied for the case of progressive gross lottery expenditure.

Proof of Proposition 3. From Eq. (4), when $\partial \tilde{\beta} / \partial y_{P}<0$ for all $y_{P}, \ell<1$ for all $y_{P}$ and gambling revenue is regressive (Lambert, 2001, pages 196-197). Similar arguments may be used for the cases of $\partial \tilde{\beta} / \partial y_{P}=0$ and $\partial \tilde{\beta} / \partial y_{P}>0$. 
Proof of Proposition 4. Define $\varepsilon_{y_{G}, y_{P}}^{*}=\partial y_{G} /\left.\partial y_{P}\left(y_{P} / y_{G}\right)\right|_{\alpha_{\mathrm{EP}}^{*}}$ and $\hat{\varepsilon}_{y_{G}, y_{P}}=\partial y_{G} /\left.\partial y_{P}\left(y_{P} / y_{G}\right)\right|_{\hat{\alpha}_{\mathrm{EP}}}$. Then, when $\partial \tilde{\beta} / \partial y_{P}>0, \alpha_{\mathrm{EP}}^{*}<\hat{\alpha}_{\mathrm{EP}}$ (from Proposition 2) and so $\varepsilon_{y_{G}, y_{P}}^{*}>\hat{\varepsilon}_{y_{G}, y_{P}}$. A similar argument can be used to show that the same result holds when $\partial \tilde{\beta} / \partial y_{P}<0$. Hence, from Jakobsson (1976, Proposition 3), it follows that $Y_{G}^{*}$ is Lorenz-dominated by $\hat{Y}_{G}$, regardless of whether $\alpha_{\mathrm{EP}}^{*}<\hat{\alpha}_{\mathrm{EP}}$ or $\alpha_{\mathrm{EP}}^{*}>\hat{\alpha}_{\mathrm{EP}}$.

Proof of Corollary 2. This result is clear from inspection of Eq. (2).

Proof of Proposition 5. The proof is similar to that of Proposition 1. Differentiating Eq. (5) with respect to $J$ and applying the usual approach to the Taylor series expansion (that is, assuming additive separability of $\beta$ in $J, \phi$ and $y_{P}$ ) yields Eq. (6).

Proof of Corollary 3. Replace $\varepsilon_{1-\alpha_{J}, J}=-\varepsilon_{\alpha_{J}, J} \alpha_{J} /\left(1-\alpha_{J}\right)$ in Eq. (6) to give Eq. (7).

\section{B Application}

For the application to the U.K. National Lottery's Saturday game, we used results from Wheeler (2018, Chapters 3 and 4).

We used Wheeler's instrumented estimate of the price elasticity of demand at average income, $\varepsilon_{\tilde{\beta}, 1-\alpha_{\mathrm{EP}}}=-0.636$ (Wheeler, 2018, Table 3.11, page 113), to estimate the slope of the demand function, $\partial \tilde{\beta} / \partial\left(1-\alpha_{\mathrm{EP}}\right)$. This is assumed to be constant for all levels of $y_{P}$. The estimate of $\tilde{\beta}$ at $\mu_{Y_{P}}$ was taken from Wheeler's semi-parametric plot of the proportion of disposable income spent on the lottery (Wheeler, 2018, Figure 4.7) and was $\tilde{\beta}\left(\mu_{Y_{P}}\right)=0.005$. The long term effective price of the Saturday game is $1-\mathrm{RTPP}=0.486$ (Wheeler, 2018, page 92). Hence $\partial \tilde{\beta} / \partial\left(1-\alpha_{\mathrm{EP}}\right)=\varepsilon_{\tilde{\beta}, 1-\alpha_{\mathrm{EP}}} \tilde{\beta}\left(\mu_{Y_{P}}\right) /(1-\mathrm{RTPP})=-0.0065$.

We fitted a truncated lognormal distribution to an estimate of the histogram data presented in Wheeler (2018, Figure 4.7) and obtained the following estimates of the expected value, standard deviation and skewness: $\mu_{Y_{P}}=456.7056, \sigma_{Y_{P}}=273.5028$ and skewness $=0.003656$. A comparison of the truncated and untruncated distributions is shown in Figure 2(b). The coefficient of variation was calculated using these parameters and estimated to be 0.5989 .

To obtain an estimate of the relationship between $\tilde{\beta}$ and $y_{P}$, we fitted a quadratic function to data points from the plot of Wheeler (2018, Figure 4.7). We used seven points, corresponding to values of the natural logarithm of disposable income at $4,4.5, \ldots, 6.5$ and 7 . The estimated equation was $\tilde{\beta}=0.0070232-4.627 \mathrm{e}^{-06} y_{P}+9.7022 \mathrm{e}^{-10} y_{P}^{2}$ at the game's effective price of 0.486 . Coefficients were statistically significant at the $5 \%$ level and the adjusted $R^{2}$ was equal to 0.956 . This gives the following function for $\tilde{\beta}: \tilde{\beta}=0.0102-4.627 \mathrm{e}^{-06} y_{P}+9.7022 \mathrm{e}^{-10} y_{P}^{2}-$ $0.0065\left(1-\alpha_{\mathrm{EP}}\right)$. This function was used to estimate the derivatives of $\tilde{\beta}$ with respect to $y_{P}$ for use in expressions for the elasticities of $\tilde{\beta}$ with respect to $y_{P}$ in Eq. (2).

Substituting our values of $c$, skewness, the relevant expressions for the elasticities and $\alpha_{\mathrm{EP}}=$ $\alpha_{\mathrm{EP}}^{*}$ into Eq. (2) leaves an expression in which the only unknown is $\alpha_{\mathrm{EP}}^{*}$. Solving gives $1-\alpha_{\mathrm{EP}}^{*} \approx$ 0.592 , implying the operator's optimal RTPP is approximately equal to 0.408 . Repeating the exercise when $\partial \tilde{\beta} / \partial y_{P}=0$ gives the value of $\alpha_{\mathrm{EP}}$ which satisfies the standard Lerner index rule, that is, $1-\hat{\alpha}_{\mathrm{EP}}=0.764$ and $\hat{\alpha}_{\mathrm{EP}}=0.236$. 


\section{References}

Baker, R., Forrest, D., and Pérez, L. (2019). Modelling demand for lotto using a novel method of correcting for endogeneity. Economic Modelling. 5

Camelot UK Lotteries Limited (2019). 2018/19 financial results. http://www.camelotgroup.co.uk/news/camelot-uklotteries-limited-201819-financial-result Accessed 24 September 2019. 3

Clotfelter, C. and Cook, P. (1987). Implicit taxation in lottery finance. National Tax Journal, 40:533-546. 6, 7, 8

Clotfelter, C. and Cook, P. (1989). Selling Hope: State Lotteries in America. Harvard University Press, Cambridge, MA. 4

Conlisk, J. (1993). The utility of gambling. Journal of Risk and Uncertainty, 6:255-275. 4, 7

DeBoer, L. (1990). Lotto sales stagnation: Product maturity or small jackpots? Growth and Change, 21:73-77. 5

Farrell, L., Hartley, R., Lanot, G., and Walker, I. (2000). The demand for lotto: the role of conscious selection. Journal of Business Economics \& Statistics, 18(2):228-241. 5, 8

Farrell, L., Morgenroth, E., and Walker, I. (1997). The long run elasticity of demand for lotto. 5

Farrell, L. and Walker, I. (1999). The welfare effects of lotto: evidence from the UK. Journal of Public Economics, 72:99-120. 5, 8

Feldstein, M. (1972). Distributional equity and the optimal structure of public prices. American Economic Review, 62(1):32-36. 7

Forrest, D., Gulley, O., and Simmons, R. (2000). Testing for rational expectations in the UK National Lottery. Applied Economics, 32(3):315-326. 5, 8

Forrest, D., Simmons, R., and Chesters, N. (2002). Buying a dream: alternative models of demand for lotto. Economic Inquiry, 40:485-496. 4, 5, 8

Friedman, M. and Savage, L. (1948). The utility analysis of choices involving risk. Journal of Political Economy, 56(4):279-304. 4

Frontier Economics (2014). The UK betting and gaming market: estimating price elasticities of demand and understanding the use of promotions. A report prepared for HM Revenue and Customs. 8

Gandullia, L. and Leporatti, L. (2018). The demand for gambling in Italian regions and its distributional consequences. Papers in Regional Science, 97:1203-1225. 6

García, J. and Rodríguez, P. (2007). The demand for football pools in Spain: The role of price, prizes, and the composition of the coupon. Journal of Sports Economics, 10:1-20. 5

Garrett, T. and Sobel, R. (2004). State lottery revenue: The importance of game characteristics. International Review of Applied Economics, 15:213-227. 5

Garrett, T. A. and Sobel, R. S. (1999). Gamblers favor skewness, not risk: further evidence from United States lottery games. Economics Letters, 63:85-90. 5

Golec, J. and Tamarkin, M. (1998). Bettors love skewness, not risk, at the horse track. Journal of Political Economy, 106:205-225. 5 
Grote, K. and Matheson, V. (2011). The economics of lotteries: A survey of the literature. College of the Holy Cross Economics Department Working Papers, 8-1-2011. 4

Jakobsson, U. (1976). On the measurement of the degree of progression. Journal of Public Economics, 5:161-168. $11,12,20$

Kahneman, D. and Tversky, A. (1979). Prospect theory: an analysis of decision under risk. Econometrica, 47:263291. 4

Kitchen, H. and Powells, S. (1991). Lottery expenditures in Canada: a regional analysis of determinants and incidence. Applied Economics, 23:1845-1852. 6

Lambert, P. J. (2001). The Distribution and Redistribution of Income. Manchester University Press, Third edition. $11,12,19$

Loistl, O. (1976). The erroneous approximation of expected utility by means of a Taylor's Series expansion: analytic and computational results. The American Economic Review, 66(5):904-910. 8

Maeda, A. (2008). Optimal lottery design for public financing. The Economic Journal, 118:1698-1718. 4, 6, 7

Matheson, V. and Grob, K. (2001). Lotto fever: do lottery players act rationally around large jackpots? Economics Letters, 83:233-237. 5

Morgan, J. and Sefton, M. (2000). Financing public goods by means of lotteries. Review of Economic Studies, 67:785-810. 4

North American Association of State and Provincial Lotteries (2019). Frequently asked questions. https://www.naspl.org/faq Accessed 24 September 2019. 3

Perez, L. and Humphreys, B. (2013). The 'who and why' of lottery: empirical highlights from the seminal economic literature. Journal of Economic Surveys, 27(5):915-940. 4, 6

Scoggins, J. (1995). The lotto and expected net revenue. National Tax Journal, pages 61-70. 5

Scott, F. and Gulley, O. (1995). Testing for efficiency in lotto markets. Economic Inquiry, 33:175-188. 5, 7

Shapira, Z. and Venezia, I. (1992). Size and frequency of prices as determinants of the demand for lotteries. Organizational Behaviour and Human Decision Processes, 52:307-318. 5

Sprowls, C. (1970). On the terms of the New York State Lottery. National Tax Journal, 23:74-82. 3

Suits, D. (1977). Gambling taxes: regressivity and revenue potential. National Tax Journal, 30:19-35. 6

Walker, I. (1998). The economic analysis of lotteries. Economic Policy, 13:359-392. 5, 7

Walker, I. and Young, J. (2001). An economist's guide to lottery design. The Economic Journal, 111:F700-F722. 5

WGR (2019). Global Lottery Market Growth (Status and Outlook) 2019-2024. https://www.wiseguyreports.com/reports/3727081-global-lottery-market-growth-status-and -outlook-2019-2024 Accessed 24 September 2019. 3

Wheeler, R. (2018). The Economics of Gambling. A Collection of Essays. PhD thesis, University of Lancaster. 4, 5, $6,8,14,15,17,20$

World Lottery Association (2018). Global lottery sales hit new heights in $2017 . \quad$ https://www.worldlotteries.org/media-news/wla-news/2792-global-lottery-sales-hit-new-heights-in-2017 Accessed 24 September 2019. 3 


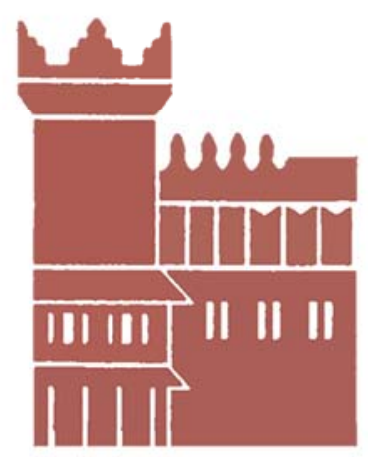

Alma Mater Studiorum - Università di Bologna DEPARTMENT OF ECONOMICS

Strada Maggiore 45

40125 Bologna - Italy

Tel. +39051 2092604

Fax +390512092664

http://www.dse.unibo.it 